\title{
INVESTIGATING THE OVERTURNING STABILITY OF UNANCHORED CONTAINERS WITH FINITE ELEMENT SIMULATIONS
}

\author{
Stefanos Gkatzogiannis ${ }^{1}$, Peter Knoedel ${ }^{2}$, and Thomas Ummenhofer ${ }^{1}$ \\ ${ }^{1}$ KIT Steel and Lightweight Structures \\ Research Center for Steel, Timber and Masonry \\ Otto-Amman-Platz 1, 76131, Karlsruhe, Germany \\ stefanos.gkatzogiannis@kit.edu \\ thomas.ummenhofer@kit.edu \\ ${ }^{2}$ Dr. Knoedel Engineering Consultants \\ Ebersteinburger Str. 9, D-76530 Baden-Baden, Germany \\ info@peterknoedel.de
}

\begin{abstract}
Unanchored containers, e.g. for toxic waste, are required to be checked against overturning under seismic actions. Usually this is done by calculating static equilibrium, therewith ensuring stiction and avoiding overturning. When concepting seismic actions as displacement-controlled base excitation with reversals, it becomes obvious that neither the beginning of an overturning motion nor the loss of stiction necessarily causes the structure to fall over. Based on a simplified rigid body assumption for the unanchored container, analytical methods were used to describe the states of no-motion, sliding, overturning and restoring of the overturning motion by reversion of the base displacement in previous work presented by the authors of the current study. Depending on the aspect ratio and a variation of friction coefficients parameter, confidence boundaries were identified, within which the structure is safe against overturning. In the present study this analysis is extended by means of numerical simulation. Dynamic finite element analyses are carried out in order to validate and extend the analytical methods of the previous paper. Successful application of finite element models allows to drop of the rigid body assumption. Thus, deformations of the container, e.g. shell modes, can be considered in a next step. This can lead to more precise and less conservative results, as with the analytical methods dissipation of energy through transformation into deformation energy or damping is neglected.
\end{abstract}

Keywords: Overturning, Rocking behavior, Toxic waste containers, Slipping, Sticking, Finite Element Method. 


\section{NOMENCALTURE}

\begin{tabular}{lll}
\hline Symbol & Unit & Meaning \\
\hline$t$ & $\mathrm{~S}$ & time \\
$F_{F}^{S}(t), F_{F}^{d}(t)$ & $\mathrm{N}$ & static and dynamic (Coulomb) friction force \\
$\mu_{S}, \mu_{d}$ & - & static and dynamic Coulomb friction coefficient \\
$G$ & $\mathrm{~N}$ & self-weight \\
$M_{T}(t)$ & $\mathrm{N} \cdot \mathrm{m}$ & tilting moment \\
$m$ & $\mathrm{~kg}$ & mass \\
$a(t)$ & $\mathrm{m} / \mathrm{s}^{2}$ & acceleration \\
$a, b, c$ & $\mathrm{~m}$ & dimensions of the body \\
$M_{R}$ & $\mathrm{~N} \cdot \mathrm{m}$ & restoring moment \\
$A$ & $\mathrm{~m}$ & amplitude of the ground motion \\
$c$ & $\mathrm{~N} \cdot \mathrm{s} / \mathrm{m}$ & damping matrix \\
$\boldsymbol{k}$ & $\mathrm{N} / \mathrm{m}$ & stiffness matrix \\
$p$ & $\mathrm{~N}$ & external load \\
$C$ & - & decay constant with no physical meaning, set equal to 0 \\
$v_{\text {sliding }}$ & $\mathrm{m} / \mathrm{s}$ & relative sliding velocity between the surfaces in contact \\
$\Delta A$ & $\mathrm{~m}$ & relative sliding between ground and base of the prism \\
\hline
\end{tabular}

\section{INTRODUCTION}

In the present study, the overturning stability of unanchored containers is investigated. A series of numerical investigations is presented, in order to validate and extend an analytical model previously proposed by the authors [1]. Although the nonlinear dynamics of rocking (tilting) and sliding oscillators have been described in the past, see [2], [3], [4] and [2], [5], [6], [7], [8] respectively, to the authors' knowledge no engineering approach existed for describing the behavior of rocking and sliding oscillators, till the recent introduction of the above-mentioned analytical model [1]. Therefore, the Lateral Force Method (LFM) suggested by Eurocode [9] (see also [10]) which leads to overconservative results for this case, had to be applied in practice until now.

Triggering point for the quasi-static analyses of [1] and the present investigations has been an industrial consulting project carried out by the second author regarding the tilting stability of unanchored steel boxes (Figure 1). These boxes are used for fire-proof storage of mercury and they are single-placed on the ground (e.g. on concrete surface) or stacked upon each other, up to three. Proof of the stacks' bearing capacity against earthquake and wind loads is required for receiving a General Type Approval by the German authorities [11]. Since the beginning of this consulting project, the over-conservatism of the LFM for the current case became apparent; loss of stiction or tilting had to be considered as loss of bearing capacity, while in reality these events can respectively lead to sliding, some bumping or even both. Therefore, the authors proposed an enhanced quasi-static solution in [1], based on the mechanical model of Figure 2, which still does not fully describe the physical reality i.e. the full dynamic response of the system, but nevertheless enabled a less conservative investigation of the problem. This was achieved by introducing four different modes for the oscillating system ground - stacked boxes, which are considered to behave as a rigid bodyi:

- The quasi-static or sticking mode with the limit conditions that the base shear does not exceed static friction (Eq. 1) and the tilting moment does not exceed the restoring moment from self-weight (Eq. 2). In this mode the stacked boxes stick to the ground and follow its displacement without any uplift or relative displacement between their base and the ground. 


$$
\begin{gathered}
F_{F}^{S}(t)=m \cdot a(t) \leq F_{F, l i m}^{s}=G \cdot \mu_{s}, \\
M_{T}(t)=m \cdot a(t) \cdot c / 2 \leq M_{R}=-G \cdot a / 2 .
\end{gathered}
$$

- The slipping mode, during which the stacked boxes slip on the oscillating ground surface due to loss of stiction. Therefore, there is relative displacement between the stack and the ground. For triggering this mode the base shear must exceed dynamic friction (Eq. 3),

$$
F_{F}^{d}(t)=m \cdot a(t) \geq G \cdot \mu_{d}=F_{F, l i m}^{d},
$$

while the tilting moment should not exceed the restoring moment from self-weight so that no uplift takes place (Eq. 2 still stands). When the system is in this mode, the accelerating base shear force is reduced during slipping compared to the stiction mode. Thus, the body is less accelerated, leading to a smaller rotation $\varphi$ if it simultaneously tilts. Therefore, for same given displacement amplitude A, the motion of the body becomes less critical.

- The rocking mode, during which uplift of a stack's bottom corner occurs. The limit condition of the base shear not exceeding friction remains unchanged (equation 1 stands) but the tilting moment should exceed the restoring moment from self-weight. As in this mode $\varphi \neq$ 0 , the two moments are estimated as follows,

$$
M_{T}(t)=m \cdot a(t) \cdot \frac{c}{2 \cdot \sin \alpha} \sin (\varphi+\alpha)>M_{R}=-G \cdot \frac{a}{2 \cdot \cos \alpha} \cos (\varphi+\alpha) .
$$

It is worth mentioning at this point that slipping, taking place simultaneous to rocking, during this mode cannot be excluded. Due to the uplift, slipping does not any longer refer to two surfaces sliding relative to each other. The Coulomb model theoretically would still stand, as it refers to acting forces and it can therefore, describe both the surface-on-surface and the edge-on-surface friction. Questions arise though, regarding its universal application due to its phenomenological nature. More complex analytical description of the limit conditions for the simultaneous initiation of slipping exceed the scope of the present study. Nonetheless, it is becoming evident from the above-presented argumentation regarding the reduced accelerating base shear during sliding, that neglecting of simultaneous sliding during rocking yields safe results.
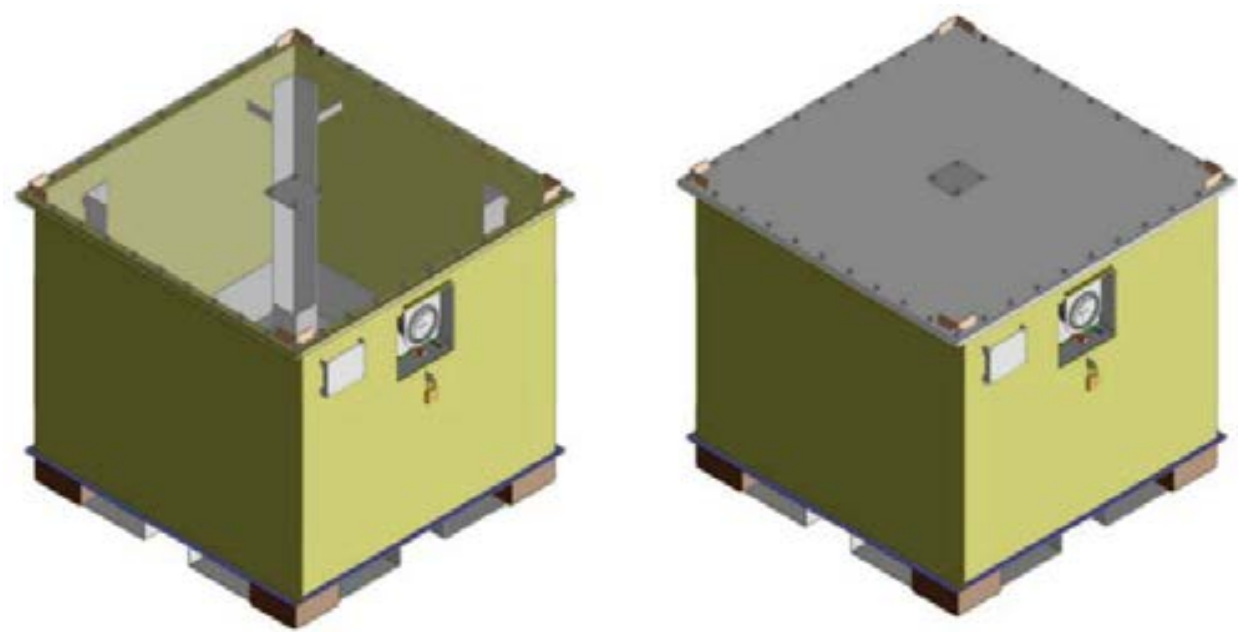

Figure 1: Outer steel box of a double wall mercury container [11] 
- Finally, overturning of the system takes place if rocking mode is initiated and the amplitude of the ground motion exceeds the half-length of the stack (we define as length the dimension of the specimen parallel to the ground motion) $A>a / 2$. In a different case $(A<a / 2)$, the overturning mode is not initiated and the previous rocking mode continues. In reality, this would lead to bumping due to consecutive ground motion reversals and loss of bearing capacity would be avoided.

It is becoming apparent from the above that the quasi-static model presented by the authors in [1] indeed describes more precisely the physical reality than the LFM, as loss of stiction leading to slipping or rocking without overturning is introduced and is not considered necessarily as loss of bearing capacity. Nonetheless, as the limit conditions of each mode are different from the rest due to changing conditions of friction and moment, the boundaries between the modes are not that discrete. Moreover, it is becoming evident that in reality two of the abovementioned modes could as well coexist and the dynamic nature of the ground motion could further improve or deteriorate the rocking behavior, an effect that cannot be described by the quasi-static model considering a base shear. In order to enable a better understanding of the involved phenomena, introduce a first step for a future parametric analysis of the problem and extend the currently proposed model a series of full dynamic numerical analyses using the FEM is carried out in the present study.
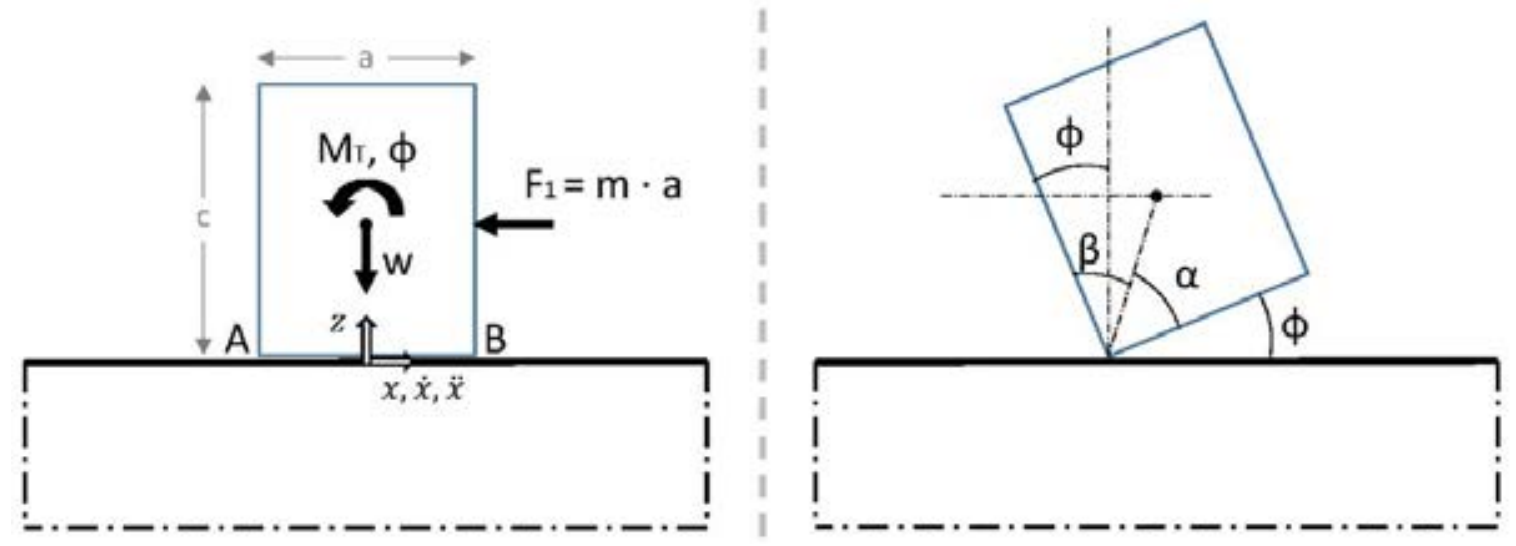

Figure 2: Mechanical model (front view); tilting/sliding body on a rigid surface [1]

\section{NUMERICAL INVESTIGATIONS}

\subsection{The finite element model}

For the present analyses, a straightforward finite element model was developed with the ground being modelled as a „,belt” of solid elements with thickness of $0.01 \mathrm{~m}$ and rigid material behavior. When a stack of more than one boxes was modelled, they were considered rigidly connected to each other as in [1] and they were therefore modelled as a single prismatic solid. A virtual density of $2.066 \mathrm{~kg} / \mathrm{m}^{3}$ was assumed for the boxes considering the steel box structure and the stored material as a homogenous mass based on the suggestion of [1]. Assumption of a rigid body for the prism simulating the single box or the stack of boxes, hereinafter called simply prism, would still stand as for the analytical model. Nonetheless, due to numerical restrictions it was modelled as an elastic body with the mechanical properties of structural steel, which anyway stands closer to physical reality.

The FE Software ANSYS [12] was applied for creating the finite element model, while the explicit dynamic solver LS-Dyna [13] was used for its solution. Based on a convergence study, solid "brick" elements with uniform dimension of $0.05 \mathrm{~m}$ were applied $(0.01 \mathrm{~m}$ in the height 
direction for the elements modelling the ground). Linear dynamic analyses were carried out (Eq. $5)$,

$$
\boldsymbol{m u ̈}+\boldsymbol{c} \dot{u}+k \boldsymbol{u}=\boldsymbol{p}(\boldsymbol{t}),
$$

while the Coulomb friction model (Eq. 6) was applied for simulating the contact between the bottom surface of the prism and the upper surface of the ground,

$$
F_{F}=\mu \cdot G \text {. }
$$

LS-Dyna estimates the friction coefficient $\mu$ by interpolating between the values of the static and dynamic friction coefficient based on the following equation (Eq. 7),

$$
\mu=\mu_{d}+\left(\mu_{s}-\mu_{d}\right) \cdot e^{-C\left|v_{\text {sliding }}\right|} \text {. }
$$

As for the present study $\mathrm{C}$ was set equal to zero, $\mu=\mu_{s}$.
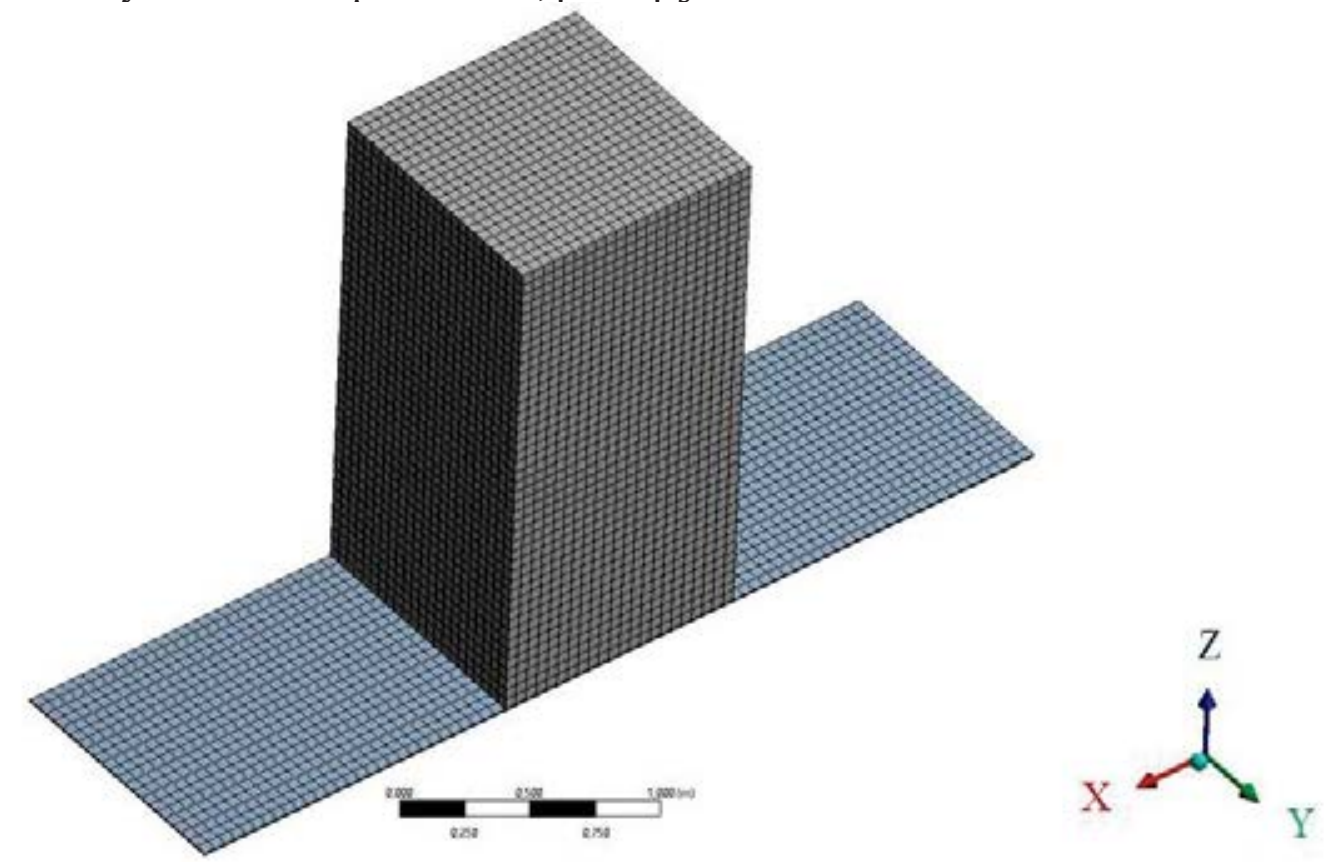

Figure 3: The FE model

\subsection{Investigated cases}

Using the above described FE model, a series of numerical analyses was investigated in order to examine the influence of different input parameters to the rocking behavior of the prism. An overview of the investigated datasets is presented in Table 1, along with the resulting rocking behavior of the prism in each invested case. The geometry of the prism is differentiated, with the height gradually increasing from $1 \mathrm{~m}$ to 2 and 3 times respectively the length dimension of a single storage box $(1.1 \mathrm{~m} \mathrm{x} 1.1 \mathrm{~m} \mathrm{x} 1 \mathrm{~m})$, for which a fundamental period of $1.98 \mathrm{~s}$ is analytically calculated in [1]. For validating this result, prior to the rest of the numerical investigations a simulation was carried out, where the prism was uplifted from the ground around its corner and was left to bounce back to the ground with only gravitational forces acting on it. In all cases, the initial horizontal position of the prism's mass center coincided with the center of the modelled ground "belt" and the gravitational force was pointing the negative direction of the $\mathrm{z}$ axis (Figure 3). Degrees of freedom outside the XZ plane were restrained, as in different case irregular bumping and unexpected displacement out of this plane occurred. This was against initial expectations, as all applied loads were on the $\mathrm{XZ}$ plane and although the result is 
closer to physical reality (for instance irregularities of real structures and ground can cause out of plane drift) in this case it was attributed to numerical effects and therefore, the additional restraints were imposed.

The seismic action was modelled in all cases as an ideal sinusoidal excitation of 5 periods in the length direction (x direction in Figure 3, the vertical component is neglected). Different values for seismic excitation were tested, with a peak ground acceleration of $1.6 \mathrm{~m} / \mathrm{s}^{2}$ applied for all analyses, but with various values for the seismic period/frequency: initially, seismic period equal to the fundamental rocking period of the prism was considered and then it was respectively increased and decreased by $10 \%$. Moreover, as one of the limit conditions, which describe the physical reality, is the relationship between friction and base shear choosing a realistic value for the friction coefficient is crucial for the current problem. Nonetheless, previous experience shows that selection of appropriate values is challenging [14]. Selection of the appropriate friction coefficient $\mu$ depends on the materials in contact, their roughness, their condition (dry or wet) etc. As a universal value cannot be proposed, two different values for the static friction coefficient 0.4 and 0.57 were tested in the current study, with the former one having been applied in [1] and the second one proposed in [15], for steel surfaces sliding on concrete. The dynamic coefficient in both cases was considered to be $50 \%$ of the static one (see relevant discussion in [1]).

\begin{tabular}{|c|c|c|c|c|c|c|}
\hline Case & $\begin{array}{l}\text { Geometry } \\
\mathrm{a} / \mathrm{b} / \mathrm{c}[\mathrm{m}]\end{array}$ & $\begin{array}{l}\text { Seismic } \\
\text { period } \\
{[\mathrm{s}]}\end{array}$ & $\begin{array}{l}\text { Friction } \\
\text { coefficients } \\
{[-]}\end{array}$ & $\begin{array}{l}\text { Activated mode of } \\
\text { rocking behavior }\end{array}$ & $\begin{array}{l}\operatorname{maxA} \\
{[\mathrm{mm}]}\end{array}$ & $\begin{array}{l}\max \Delta \mathrm{A} \\
{[\mathrm{mm}]}\end{array}$ \\
\hline A1 & $1.1 / 1.1 / 1$ & 1.98 & $0.40 / 0.20$ & sliding - sticking & \pm 158 & 31 \\
\hline A2 & $1.1 / 1.1 / 1$ & 2.18 & $0.40 / 0.20$ & sliding - sticking & \pm 193 & 37 \\
\hline A3 & $1.1 / 1.1 / 1$ & 1.78 & $0.40 / 0.20$ & sliding - sticking & \pm 128 & 25 \\
\hline A4 & $1.1 / 1.1 / 1$ & 1.98 & $0.57 / 0.29$ & sliding - sticking & \pm 159 & 14 \\
\hline A5 & $1.1 / 1.1 / 1$ & 2.18 & $0.57 / 0.29$ & $\begin{array}{l}\text { tilting \& bumping - } \\
\text { sticking }\end{array}$ & \pm 192 & 20 \\
\hline A6 & $1.1 / 1.1 / 1$ & 1.78 & $0.57 / 0.29$ & $\begin{array}{l}\text { tilting \& bumping - } \\
\text { sticking }\end{array}$ & \pm 128 & 13 \\
\hline B1 & $1.1 / 1.1 / 2.2$ & 2.50 & $0.57 / 0.29$ & tilting - sticking & \pm 257 & 24 \\
\hline $\mathrm{C} 1$ & $1.1 / 1.1 / 3.3$ & 3.10 & $0.57 / 0.29$ & tilting - sticking & \pm 386 & 22 \\
\hline $\mathrm{C} 2$ & $1.1 / 1.1 / 3.3$ & 1.55 & $0.57 / 0.29$ & tilting - overturning & \pm 399 & $71 *$ \\
\hline
\end{tabular}

\section{RESULTS AND DISCUSSION}

\subsection{Presented results}

For the shake of clarity, only selected results of the above-presented investigations are presented, as some models produced similar results with each other. At first the results of the fundamental period test and the models A2 and A5 regarding the case of a single box are presented. In the former case, the vertical displacement of the prism's upper left corner over time (Figure 5) along with contours of vertical displacement are presented. Tappauf and Taras [16], [17] found quite similar results when they investigated the partial uplift of big tanks. In that case though, a time offset between the bumps was documented due to the sloshing wave along the tanks diameter. For the models A2 and A5, both diagrams of horizontal displacement of the ground and the prism's bottom and top (right corner node for both, Figure 6,7) and contours of 
horizontal displacements at arbitrary but representative times of the simulation (Figure 8,9) are presented. Later on, $\mathrm{C} 1$ and $\mathrm{C} 2$ referring to the case, where the height of the prism is three times its length and exhibiting respectively the modes of tilting and overturning are discussed. The results are presented in an analogous way as of those for the models A2 and A5, see Figure 10 $-13$.

\subsection{Validation of analytically calculated fundamental period}

The contours of vertical displacement at three different moments of the simulation, at time $0 \mathrm{~s}, 0.192 \mathrm{~s}$ and $0.360 \mathrm{~s}$, are given in Figure 4. The results of the vertical displacement of the upper left corner over time are provided in Figure 5. During the simulation and after the first contact of the bottom left corner with the ground, the prism entered an irregular bumping sequence, which becomes obvious from the great number of hills and valleys in the diagram of Figure 5, including horizontal displacements as well (x axis). As a result, for the estimation of the fundamental rocking history, only the results up to this moment of first contact are considered. The time, until the initiation of this contact i.e. at $0.384 \mathrm{~s}$ constitutes a quarter-period, therefore a fundamental period of $1.536 \mathrm{~s}$ is estimated. A significant deviation of $20 \%$ with the analytically estimated fundamental period $\left(\mathrm{T}_{\text {analytical }}=1.98 \mathrm{~s}\right.$ is given in [1], Eq. $19, \mathrm{~T}_{\text {num }} / \mathrm{T}_{\text {ana- }}$ lytical $=80 \%$ ) is met.

\subsection{Models A1 - A6}

For all the investigations with the prism geometry corresponding to the case of a single box, and despite any change in seismic action no overturning was documented. When the lower values of friction were considered (0.4-0.2 for models A1-A3) slight sliding during initiation of the seismic excitation was observed and the prism stuck to the ground for the rest of the reversals. It has to be highlighted, that after the end of the seismic action the prism slided back to its initial position. The diagram of the horizontal displacements over time presented in Figure 6 and the horizontal displacement contours from the first period of the seismic excitation presented in Figure 8 from the model A2, for which the most severe sliding of approximately 36 $\mathrm{mm}$ was observed, validate the above observations.

Nonetheless, when the friction coefficients were increased and for the models A5 and A6 with the lowest and highest seismic periods (A4 exhibited similar behavior with the previous), the prism during the initiation of the seismic action instead of sliding tilted with a slight uplift of the bottom corner on the side of displacement's direction being documented. At the same time the stiction between the left bottom corner and the ground led to a hopping of the prism towards the ground displacement direction, which introduced relative displacement between the ground and the prism. This could be mistakenly attributed to some sort of simultaneous sliding. Observing the diagram of horizontal displacements for the model A5 though, presented in Figure 7, it can be seen that in contrast to the case of A2 the prism exhibits higher horizontal displacement than the ground already from the first quarter of the first loading period. This is physically impossible to be caused by sliding. After the first hopping another uplift of lower magnitude is initiated, after the end of which the prism sticks to the ground for the rest of the excitation. The contours of Figure 9 offer a clearer overview of the above-described phenomenon. Once again after the end of the excitation, reversed uplift and hopping restores the prism to its original position. 


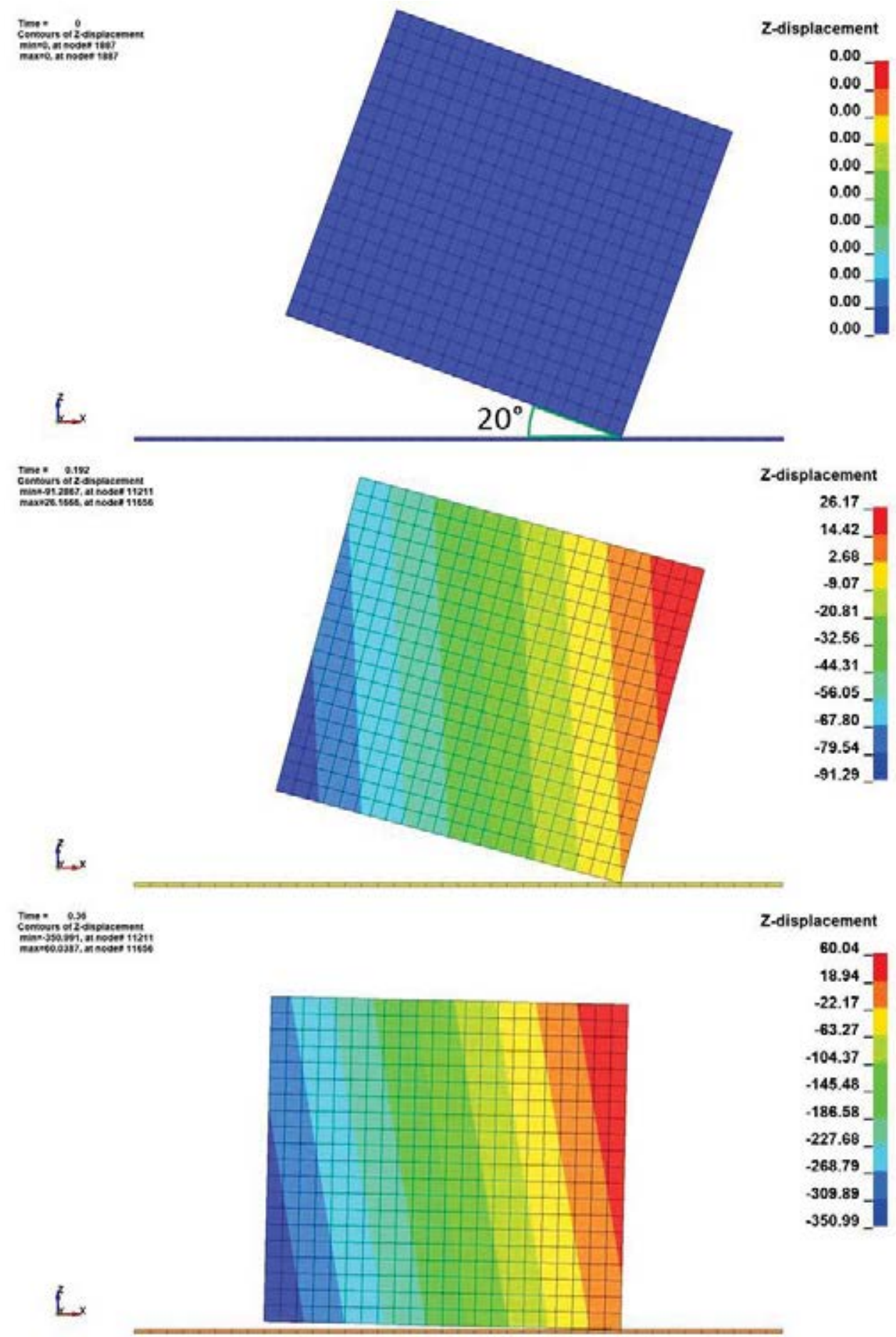

Figure 4: Checking the rocking fundamental period of the prism with dimensions $1.1 \mathrm{~m} \times 1.1 \mathrm{~m} \times 1 \mathrm{~m}-$ Contours of vertical displacement, given at mm, at time $0 \mathrm{~s}, 0.192 \mathrm{~s}$ and $0.360 \mathrm{~s}$ 


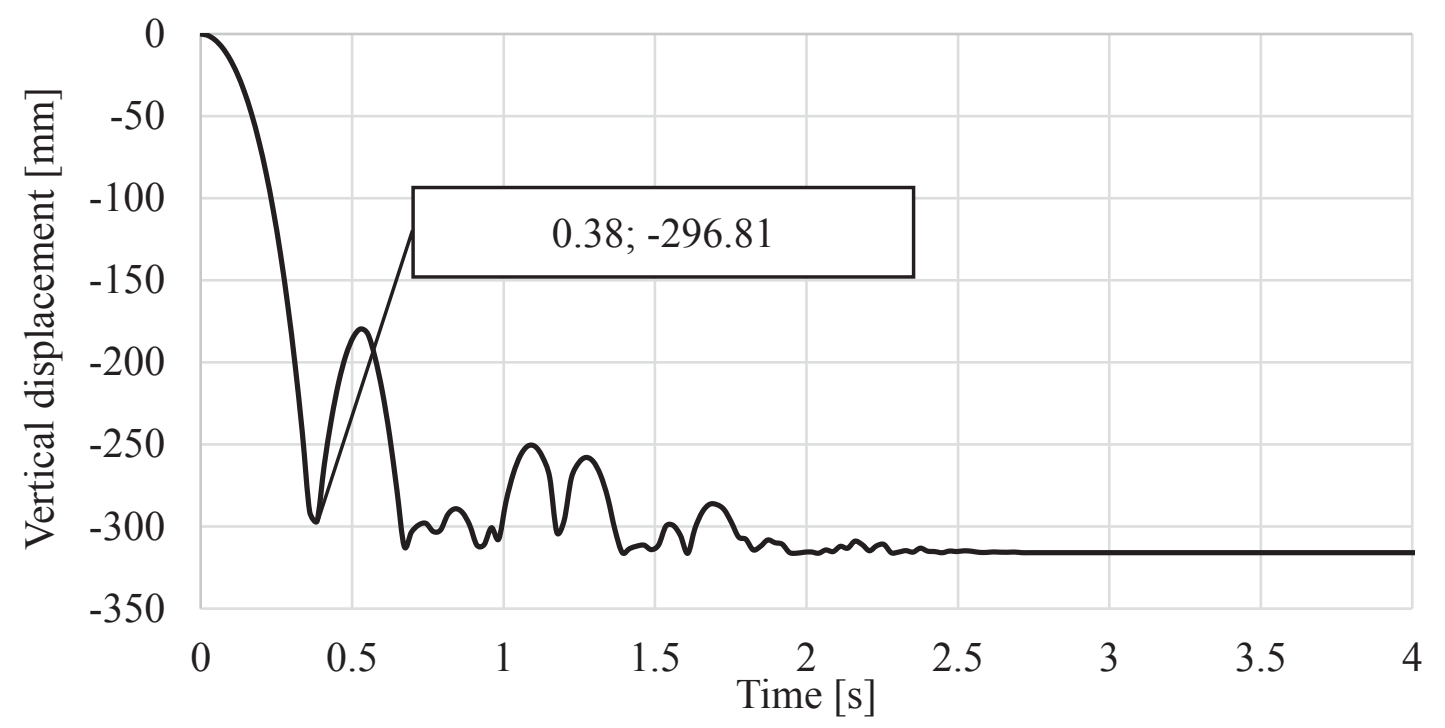

Figure 5: Vertical displacement of the upper left corner over time

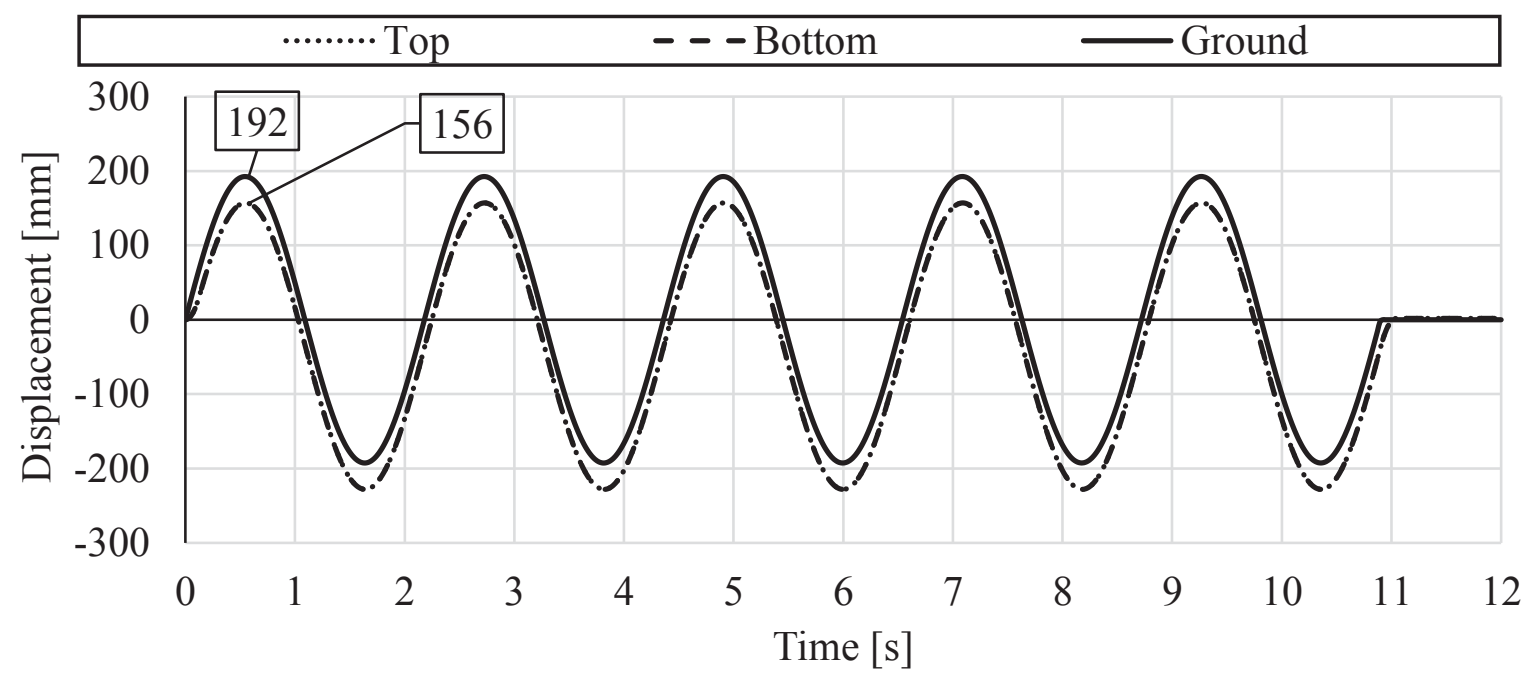

Figure 6: Horizontal displacement of the ground and the top and bottom surfaces of the prism for model A2

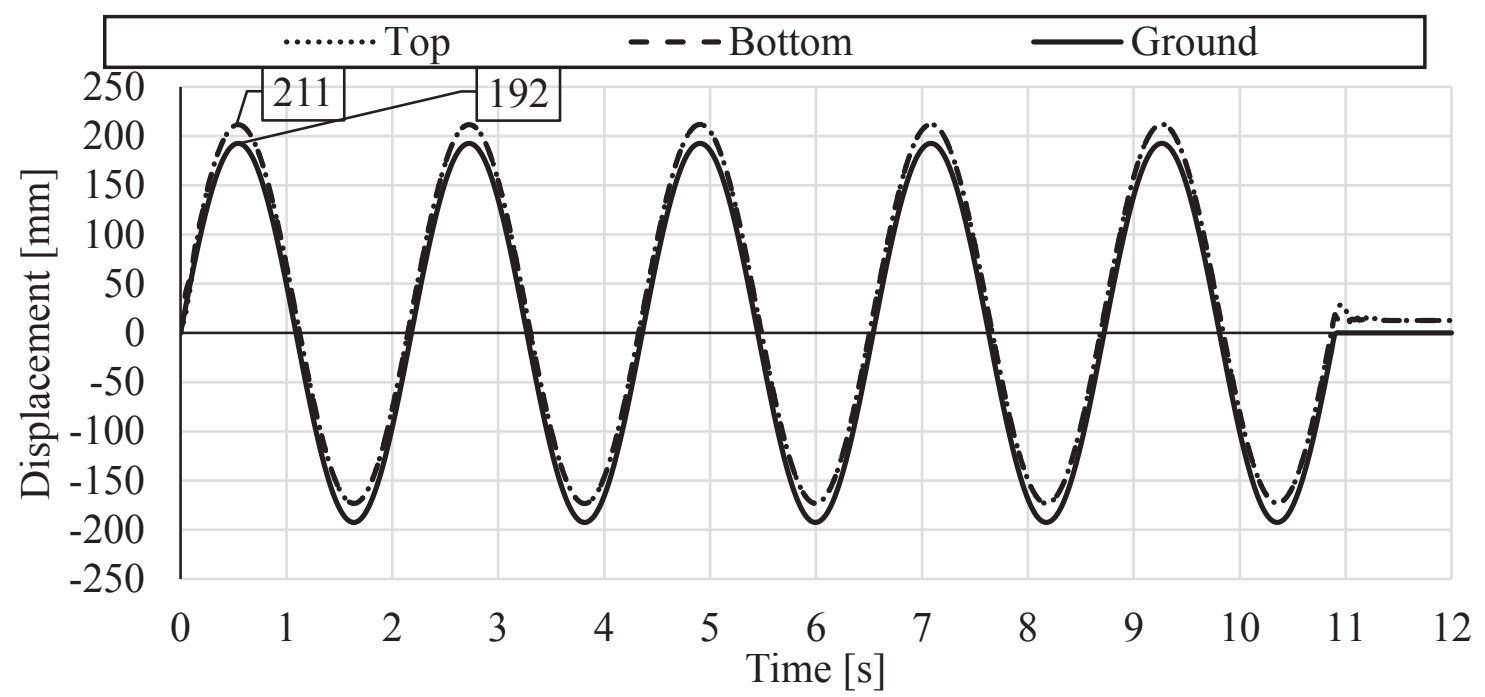

Figure 7: Horizontal displacement of the ground and the top and bottom surfaces of the prism for model A5 
This effect of sliding back and forth at the beginning and at the end of the seismic motion is attributed to the simplified modelling of the ground motion. At the beginning and at the end of the loading, sinusoidal displacement is respectively abruptly initiated and changed back to nomotion. With a steady state harmonic oscillation, maximum speed is given at zero-crossing. Thus, in the present way of modelling the displacement, a very high acceleration is imposed onto the prism at these singular points. This in turn activates a very high impulse of inertia forces, which cause a short phase of sliding. This effect is a shortcoming when driving the model by displacements instead of prescribed accelerations. However, in previous work of the authors (e.g. [18], [19]) it was shown, that displacement drives make nonlinear systems with plasticity easier to handle. Note, that the simulations given in [14] are different: there, the displacements of the hammering pin are a priory unknown, and cannot be used to drive the system (see discussion in [14] chap. 5.1). In future simulations, a ramp-up as smooth transition between the states of motion and no-motion could be introduced.

\subsection{Models B2, C1, C2}

The increase of height in the model B2 being twice the length and width of the specimen led to qualitatively similar results to the models A5 and A6 with more severe tilting at the initiation of the excitation though, followed once again by a continuous stiction mode till the end of the excitation. Nonetheless, further increase of height in the model $\mathrm{C} 1$ led to significant tilting, taking place for more than the first 3 periods of seismic excitation as it is becoming obvious this time by both the horizontal displacement diagrams of Figure 9 and the horizontal displacement contours of Figure 12, but still without leading to overturning. As it can be seen in Figure 11 and Figure 13 though, this was the case for the analysis of model $\mathrm{C} 2$, for which the seismic frequency was doubled. Tilting initiated at the beginning of the seismic excitation caused uplift at first to the right side of the prism (direction of the seismic excitation at first quarter of the period), which was reversed after the reversal of the seismic displacement during the second quarter of the seismic period, which initiated at $0.389 \mathrm{~s}$. This almost caused the overturning of the prism, which was nevertheless stalled due to the second reversal of the ground displacement. The prism remained at its uplifted position for the third quarter of the seismic period $(0.778 \mathrm{~s}-$ $1.167 \mathrm{~s}$ ) and finally after the third reversal and initiation of the fourth quarter of the $1^{\text {st }}$ seismic period overturning was completed leading to loss of the bearing capacity. Once again, the prism carried out several consecutive hops, when in rocking position, during the second and third quarters. 


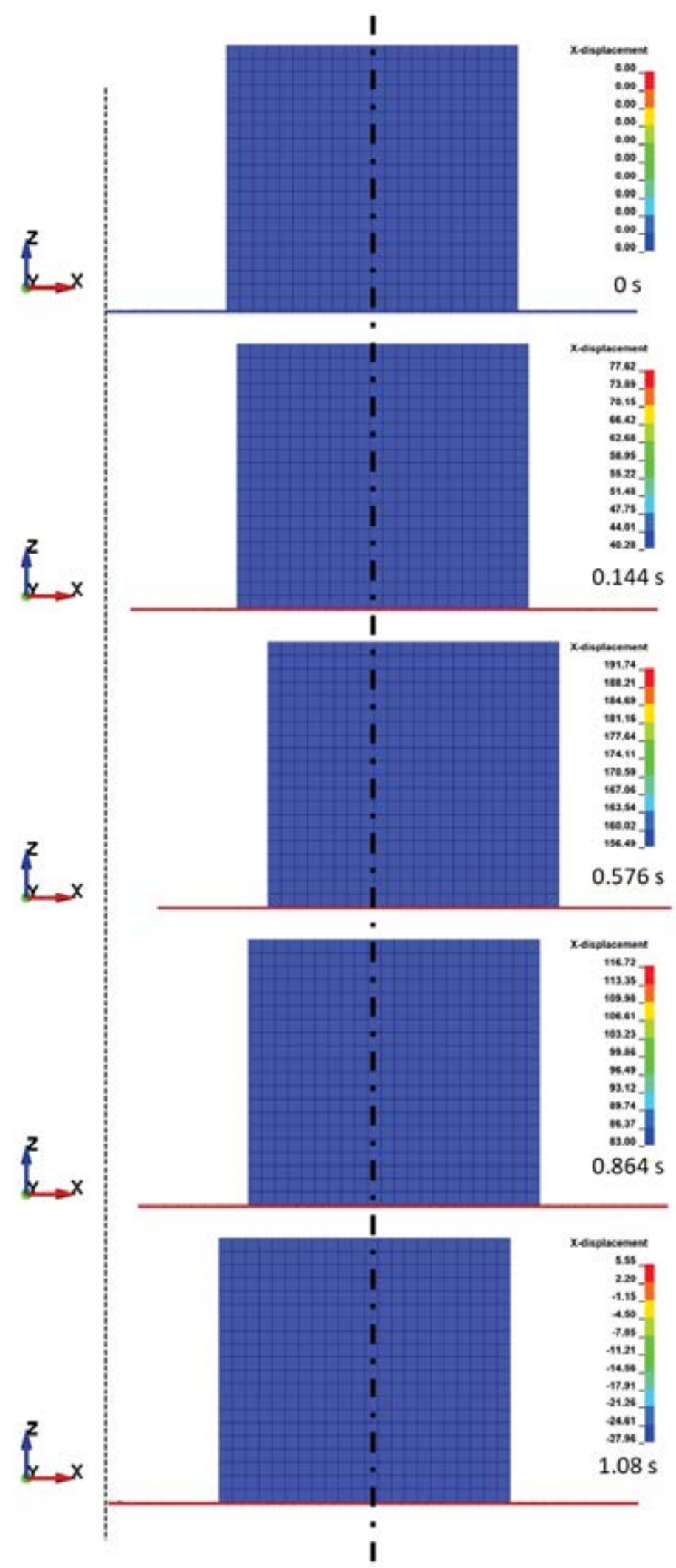

Figure 8: Horizontal displacement contours at arbitrary moments of the $1^{\text {st }}$ period of the seismic loading for the model A 2 - the broken and the dashed broken line show respectively the initial horizontal position of the ground belt's left edge and the prism's mass center 


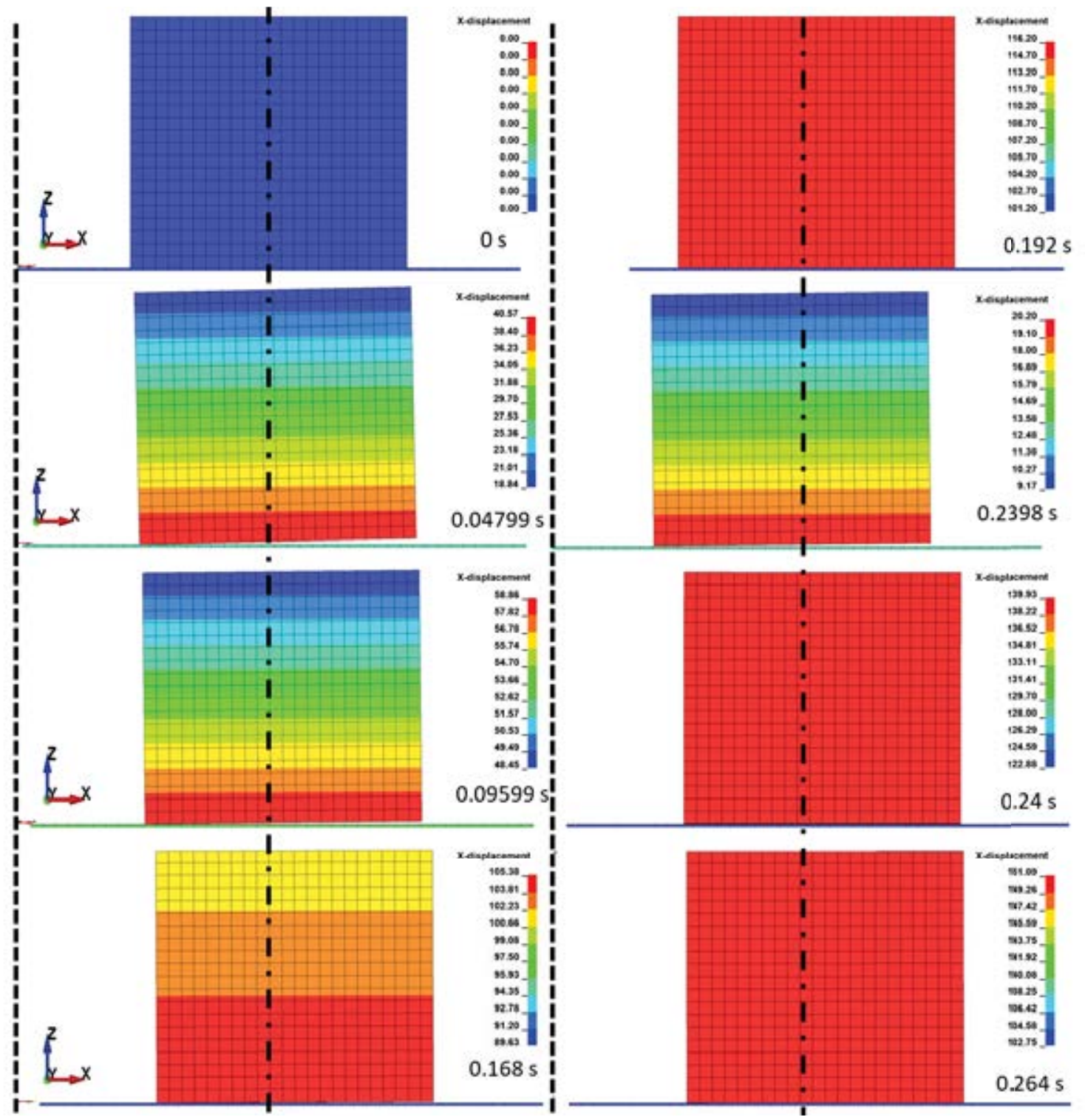

Figure 9: Horizontal displacement contours taken at arbitrary moments of the $1^{\text {st }}$ period of the seismic loading for the model A5 - the broken and the dashed broken line show respectively the initial horizontal position of the ground belt's left edge and the prism's mass center

\section{SUMMARY AND CONCLUSIONS}

A series of numerical analyses was carried out in order to investigate the rocking behavior of a single or several steel boxes stacked upon each other, used for safe deposition of chemicals. Goal of the investigations was to test assumptions stated during the introduction of an analytical model in a previous study [1], prove the conservatism of this analytical model and act as a firststep towards the development of a numerical model, which will enable a parametric analysis of the investigated problem. The following conclusions were drawn:

- The numerically estimated rocking fundamental period of the investigated prism deviates significantly from the analytically calculated $(\sim 20 \%)$. Further investigations are recommended in order to clarify the reasons for this discrepancy.

- The over-conservatism of the approach of the LFM is proven: It is shown that in many cases the loss of stiction does not lead to loss of bearing capacity. 


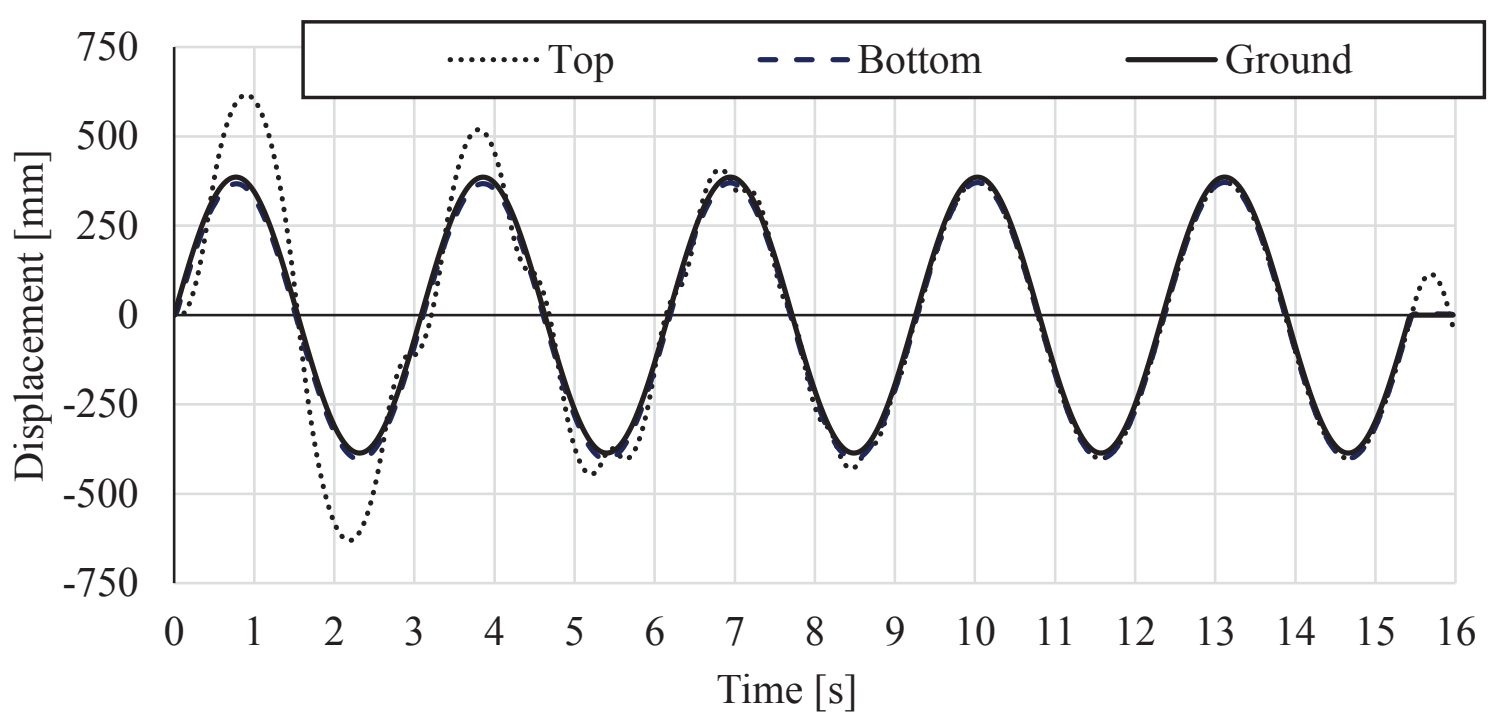

Figure 10: Horizontal displacement of the ground and the top and bottom surfaces of the prism for model C1

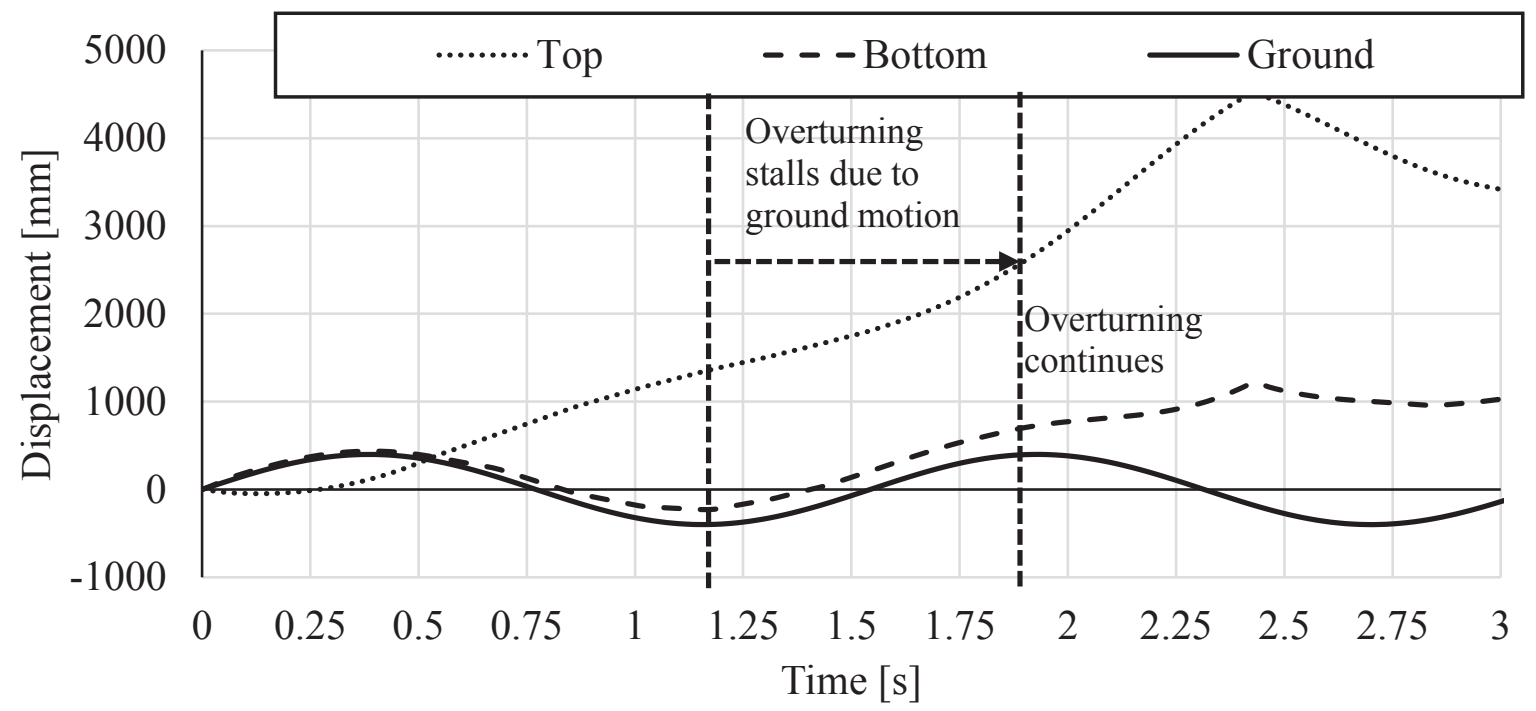

Figure 11: Horizontal displacement of the ground and the top and bottom surfaces of the prism for model C2

- It is shown that the analytical model proposed by the authors is as well conservative, although less than the LMF method. For instance overturning of a structure, although initiated can be stalled due to the ground motion, an effect which cannot be described by the quasistatic model.

- The assumption stated above that different modes (sliding and sticking) can both be met during a seismic excitation is proven. This as well cannot be described by the quasi-static analytical model.

- The above-stated assumption that appropriate selection of friction coefficients is crucial is validated: for identical conditions increase of the static and dynamic friction coefficient from 0.4 to 0.57 and from 0.2 to 0.29 led to change of the rocking behaviour.

- Hopping due to bumping of the prism due to initial tilting of its front corner and action of horizontal stiction forces on its back corner, produces relative displacement between the prism and the ground. This as well cannot be described the quasi-static analytical model introduced by the authors. 


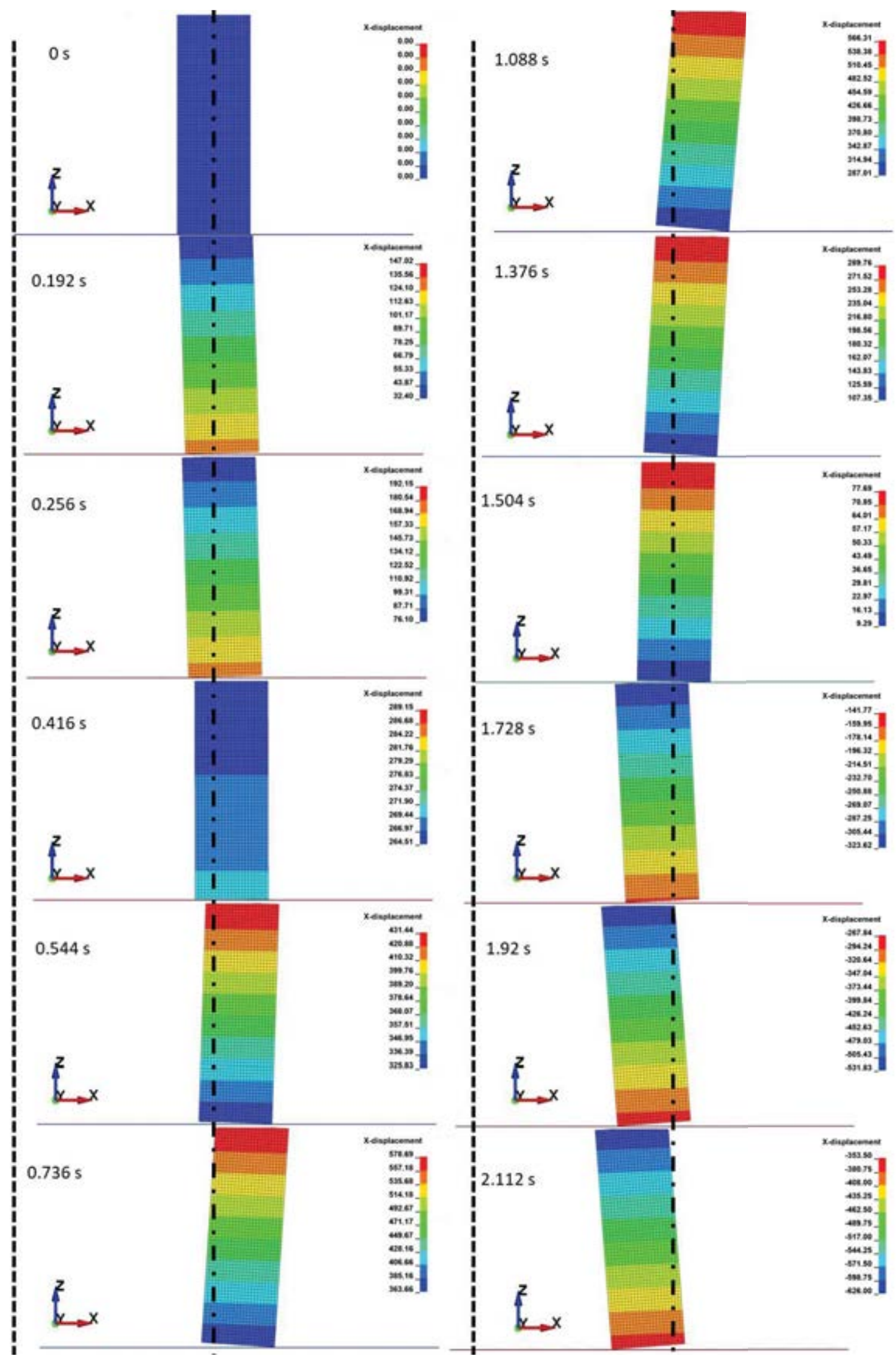

Figure 12: Horizontal displacement contours taken at arbitrary moments of the $1^{\text {st }}$ period of the seismic loading for the model $\mathrm{C} 1$ - the broken and the dashed broken line show respectively the initial horizontal position of the ground belt's left edge and the prism's mass center 


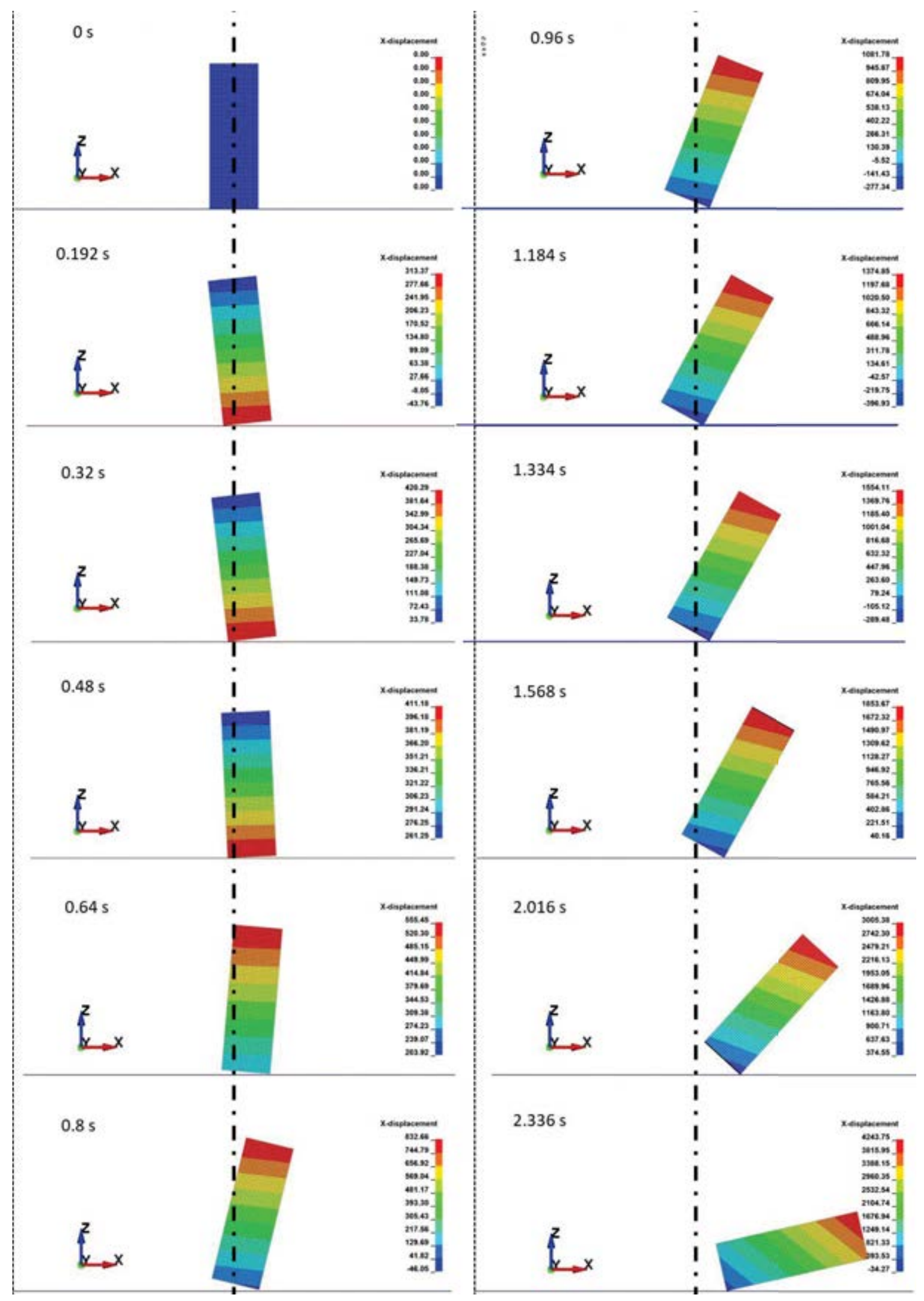

Figure 13: Horizontal displacement contours from the model C2 taken at arbitrary moments the broken and the dashed broken line show respectively the initial horizontal position of the ground belt's left edge and the prism's mass center 
In general, numerical investigations of the current problem show great potential for better understanding of the investigated systems behavior and for achieving less conservative results. A parametrization of the present model in future work in combination with variated and even real seismic excitation, could enable the estimation of the precise limits of transition from one mode of rocking behavior to another. It could be as well interesting to introduce a vertical seismic component, which assumingly could lead more easily to loss of stiction. Finally more detailed modelling of the structures geometry and physical properties could contribute to more accurate solutions.

\section{ACKNOWLEDGEMENT}

The authors would like to thank the company UTM Umwelt-Technik-Metallrecycling GmbH for allowing the use of industrial data for the present academic project.

\section{REFERENCES}

[1] P. Knoedel, S. Gkatzogiannis, T. Ummenhofer, A Simple Stick-Slip Model for the Overturning Stability of unanchored Containers. Published in Butenweg, C., Hoffmeister, B., Holtschoppen, B., Klinkel, S., Rosin, J., Schmitt, T. (eds), Seismic Design of Industrial Facilities 2020. Proceedings of the 2nd International Conference on Seismic Design of Industrial Facilities, Apprimus Verlag, Aachen, 201-210, 2020.

[2] K. Klotter, Technische Schwingungslehre, Erster Band: Einfache Schwinger. Teil B: Nichtlineare Schwingungen, 3d Edition. Auflage, Springer-Verlag, Berlin 1980.

[3] M.J. DeJong, E.G. Dimitrakopoulos, Equivalent Rocking Systems: Fundamental Rocking Parameters. Proc., 15 WCEE 15th World Congress on Earthquake Engineering, Lisbon, Portugal, September 24-28, 2012.

[4] M.F. Vassiliou, N. Makris, Dynamics of the Vertically Restrained Rocking Column. J. Eng. Mech. 141 (12), published online May 19, 2015.

[5] J.P. den Hartog, Mechanical Vibrations, Third Edition. McGraw-Hill New York, London, 1947.

[6] N. Gaus, Zur Ermittlung eines stochastischen Reibwerts und dessen Einfluss auf reibungserregte Schwingungen. Diss. Karlsruher Institut für Technologie, Schriftenreihe des Instituts für Technische Mechanik, Band 23, 2014.

[7] R.I. Leine, D.H. van Campen, A. de Kraker, L. van den Steen, Stick-Slip Vibrations Induced by Alternate Friction Models. Nonlinear Dynamics 16, 41-54, 1998.

[8] H.-K. Hong, C.-S. Liu, Coulomb Friction Oscillator: Modelling and Responses to Harmonic Loads and Base Excitations. Journal of Sound and Vibration, 229 (5), 1171-1192, 2000 .

[9] EN 1998-1: 2004 (English), Eurocode 8: Design of structures for earthquake resistance - Part 1: General rules, seismic actions and rules for buildings. 
[10] P. Knoedel, T. Ummenhofer, Mass Variation with dissipative Steel Structures under Seismic Loads. Published in Papadrakakis, M., Fragiadakis, M. (eds), Proc. COMPDYN 2017, $6^{\text {th }}$ ECCOMAS Thematic Conference on Computational Methods in Structural Dynamics and Earthquake Engineering, 15-17 June 2017, Rhodes Island, Greece, 4928-4942, 2017.

[11] Allgemeine bauaufsichtliche Zulassung Z-38.12-294, Kubische doppelwandige Behälter aus Stahl; Hg Storage 150L. Entwurf, Deutschen Institut für Bautechnik, Berlin, Entwurf 2019. Antragsteller: UTM Umwelt-Technik-Metallrecycling GmbH, Alt-Herrenwyk 12, D-23569 Lübeck.

[12] ANSYS® Academic Research, Release 21.1, Help System, ANSYS, Inc., 2021.

[13] LS-DYNA, Theory Manual, Livermore Software Technology Corporation (LSTC), Livermore California, 2016.

[14] S. Gkatzogiannis, Finite Element Simulation of Residual Stresses from Welding and High Frequency Hammer Peening. Doctoral Dissertation, Department of Civil Engineering, Geo and Environmental Sciences, Karlsruhe Institute of Technology, 2020.

[15] B. G. Rabbat, H. G. Russel, Friction Coefficient of Steel on Concrete or Grout. J. Struct. Eng. 111 (3), 505-515, 1985.

[16] C. Tappauf, A. Taras, Deformation and Strain Histories in Shell-to-Base Joints of Unanchored Steel Storage-Tanks during Seismic Loading. STESSA 8th Int. Conf. on Behavior of Steel Structures in Seismic Areas, Shanghai, China, July 1-3, 2015.

[17] C. Tappauf, Ermüdungsverhalten von unverankerten Stahltanks bei Erdbeben. Dissertation, TU Graz, Juni 2018.

[18] P. Knoedel, J. Hrabowski, Yield Limit vs. Behaviour Factor in Seismic Design. Proceedings, NSCC 2012 Nordic Steel Construction Conference, 5-7 September 2012, Oslo, Norway, 147-155, 2012.

[19] P. Knoedel, T. Ummenhofer, Time History Simulation in Seismic Design. Contribution 379 (USB). Heinisuo, M., Mäkinen, J. (eds).: Proceedings, NSCC-2015 Nordic Steel Construction Conference 2015, Tampere, Finland, 23-25 September, 2015.

\footnotetext{
${ }^{i}$ for stacked boxes this implies, that either gapping between the boxes is counterbalanced by the selfweight or the boxes are bolted; the stack remains rigid, "whipping" is excluded.
} 